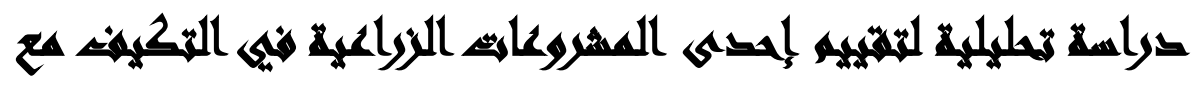

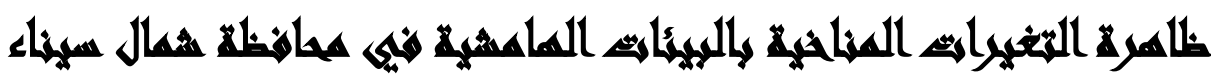 [Ir]
}

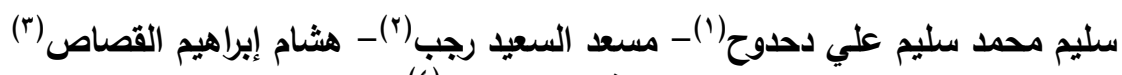

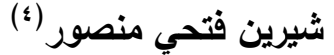

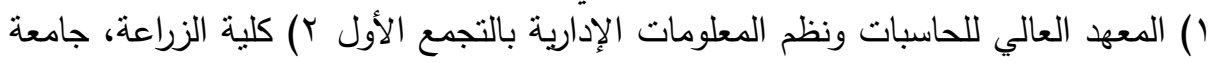

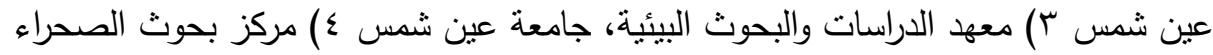

\section{المستخلصن}

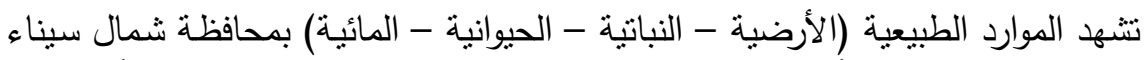

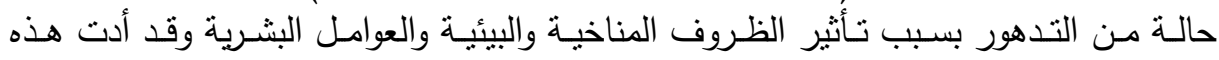

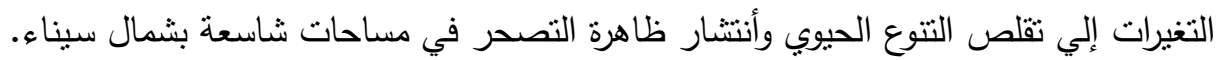

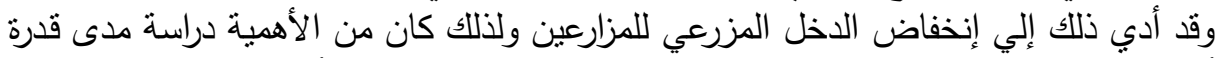

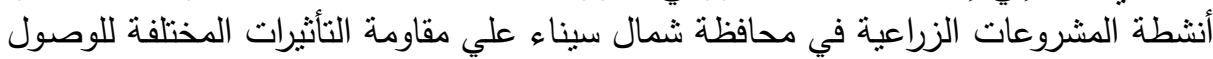

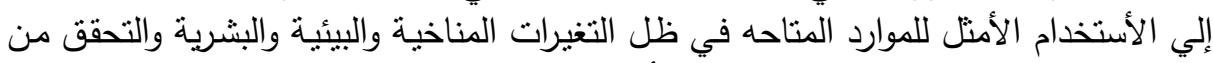

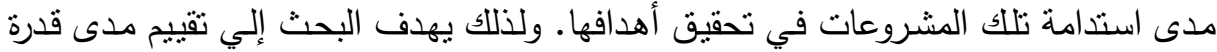

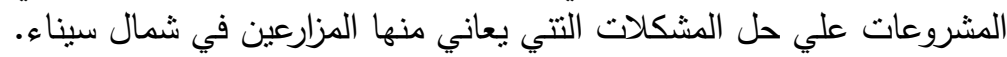

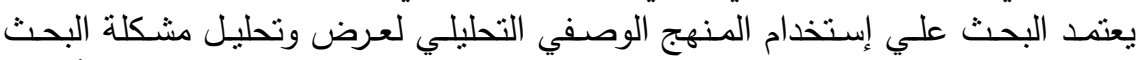

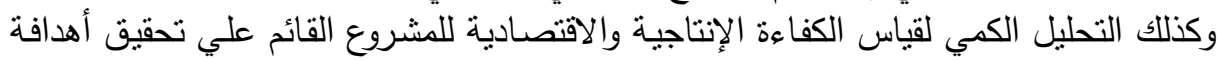

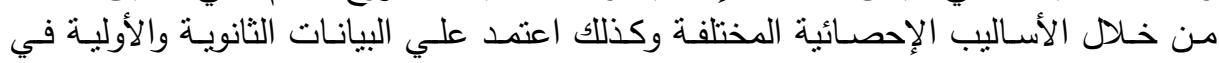

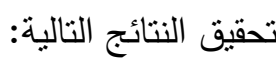

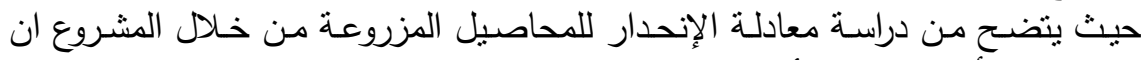

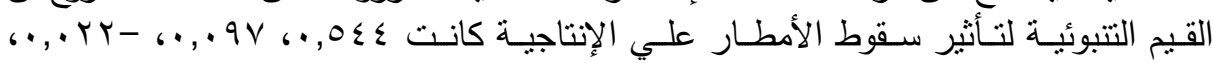

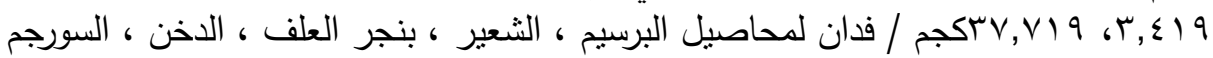

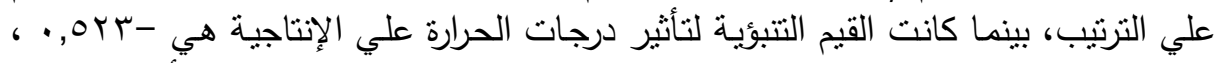

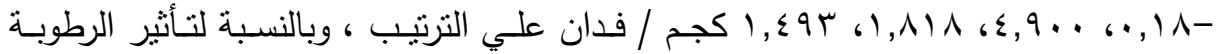

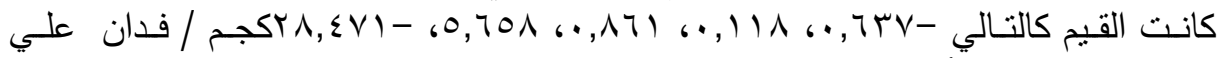

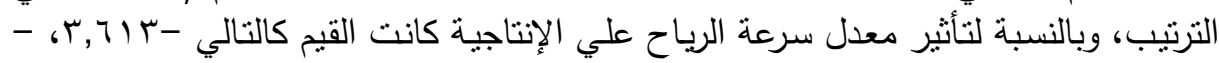

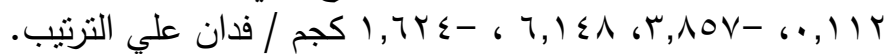




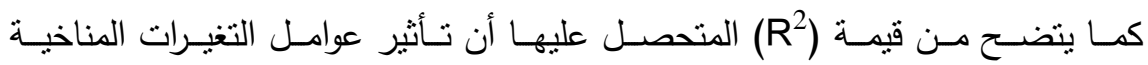

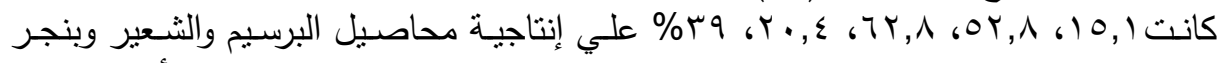

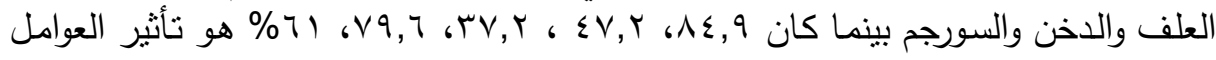

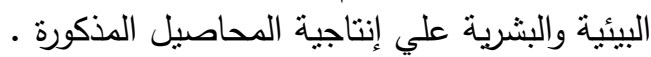

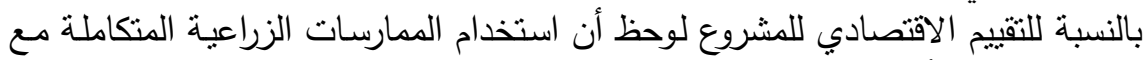

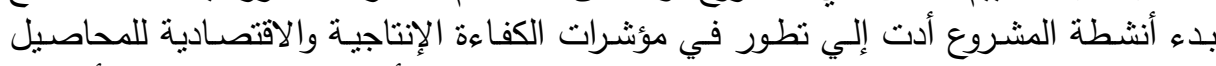

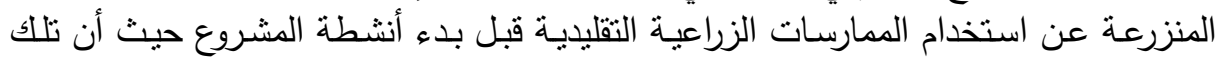

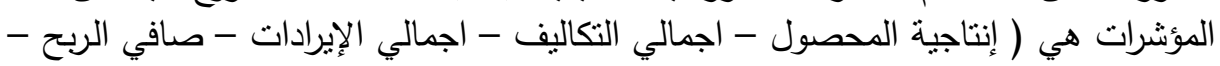

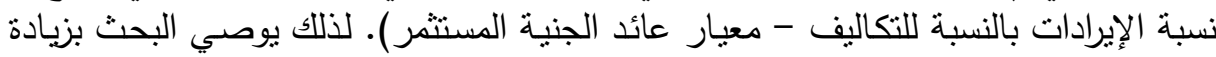

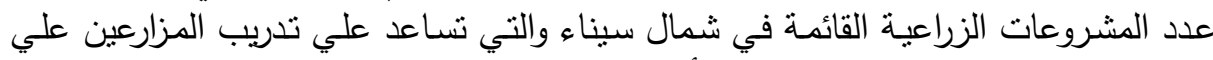

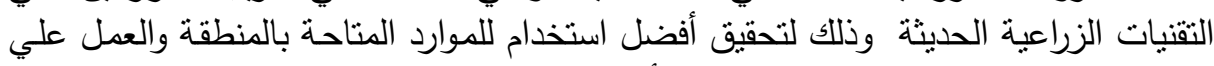
انتاج سلالات جديدة من المحاصيل التي تتأقلم مع ظروف المنطفة التطفة وذللك لزيادة الإنتاجية.

\section{ranall}

تشهر الموارد الطبيعية ( المواردالأرضية والنباتية والحيوانية والمائية ) فى شبة جزيرة سيناء حالة من التدهور الثديد بسبب نأثثر الظروف المناخية والبيئية او العوامل البشرية (مثل انتتار القرى والمجمعات السياحيه وإقامة القرى والمدن على مناطق المراعى الطبيعية)، وقد

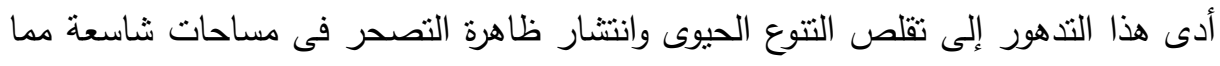
نتج عنه تدني انتاج الحاصلات الزراعية وأعلاف الحيوانات وإنتاج الخشب والطاقة وإلى زيادة الفقر وازدياد الضغط على الموارد الطبيعية. هذا بالإضافة الى انتشار ظاهرة الملوحة التى لنى

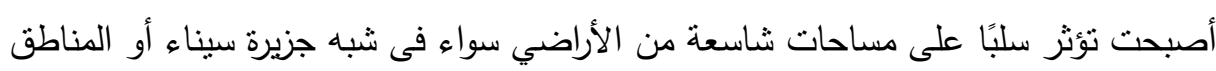
الساحلية فى شمال البلاد وتأثر مساحات كبيرة من الاراضى الخصبة فى الدلتا ووادى النيل

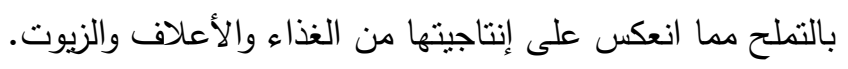

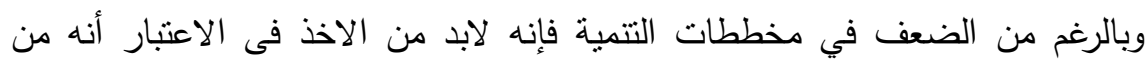
الضرورى الاهتمام بالتتمية الثاملة لهذة المناطق لكثير من مقوماتها الاستراتيجية والامنية

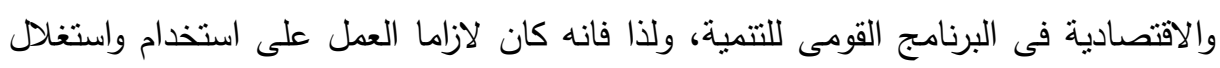
تللك الموارد المتاحة (التربة المالحة والمياه العادمة) باساليب مثلى فى زراعة المحاصيل العلفية التى تتحمل الملوحة (لتغذية الحيوانات) وكذلك زراعة بعض محاصيل الحبوب والزيوت حيث 
يمكن أن يسهم ذلك في تطويرالنظام الزراعى فى تللك المناطق، ورفع القدرة المعيشية للسكان

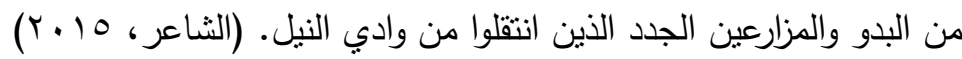
لذا تعتبر عملية التقييم من الأمور المهمة للمشروعات التتموية حتى تسنطيع الاستمرار

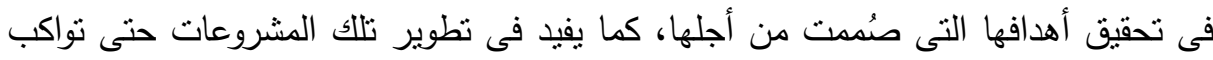

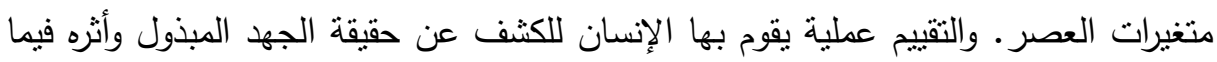
كان ينبغى الوصول إليه مستخدمًا معايير ومقاييس يحددها هو بنفسه، وفى لغة الاجتماعيين يعنى قياس قيمة وكفاية وفعالية العمل الاجتماعى أو النظام الاجتماعى والأنماط السلوكية

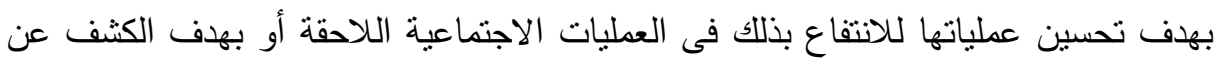

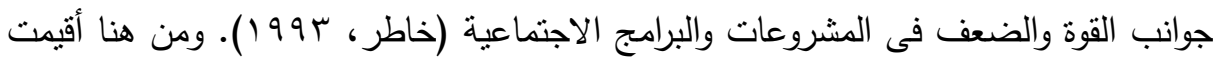
العديد من المشاريع الزراعية لدراسة مدى تكيف المحاصيل المزروعة على التغيرات المختلفة التي تؤثز على الإنتاج الزراعي سواء كانت طبيعية أو بشرية بمحافظة شمال سيناء وكيفية

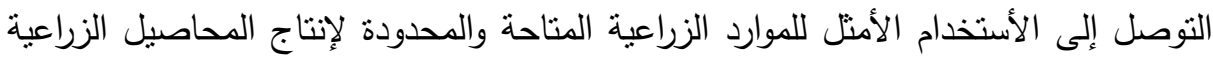
والذى يحقق أعلي صافي دخل مزرعى منها (Mansour,2017)، ولذلك فإن اهمية هذا لتها البحث يتمثل فى دراسة مدى أستمرارية و إستدامة تلك المشاريع وقدرتها على حلى المشكلات المختلفة التى تواجه المزارعين بتلك المناطق.

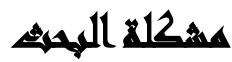

تعاني محافظة شمال سيناء من التذهور الثنديد نتيجة التغيرات المناخية والبيئية والبشرية وأنتشار ظاهرة التصحر في مساحات كبيرة مما أثر على إنتاجية الحاصلات الزراعية وبالتالى لنئه

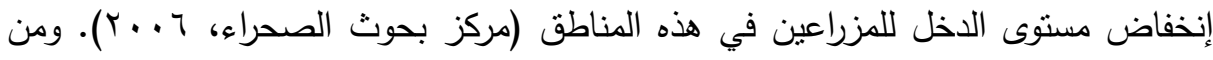
هنا تكمن المشكلة البحثية في قدرة أنشطة المشروعات الزراعيةفى مناطق عملها بمحافظة بهنة

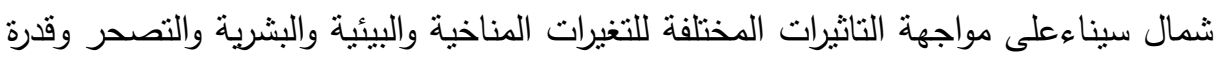
المزارعين على التكيف مع هذه التغيرات وبالتالى تحسين مستوى معيشتهم، وهل ما تسعى اليه

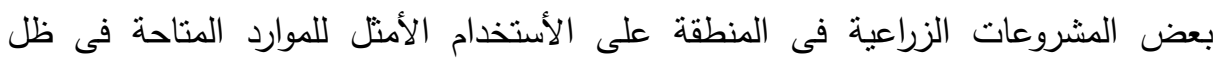
التغيرات المناخية ومدى الأستدامة الزراعية لهذه المشاريع القائمة.

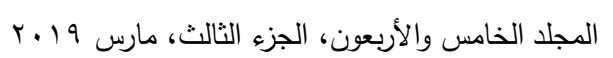




\section{أهساهث المهيد}

يهدف البحث إلي تقييم مدى قدرة المشروعات على حل الششكلات التى يعاني منها المزارعين فى انخفاض إنتاجية المحاصيل والتكيف مع ظروف البيئات الهامشية فى محافظة شمال سيناء - اء

ويتحقق هذا الهذف من خلال: أ-الوقوف علي مدي تأثر الإنتاج الزراعي بالتغيرات المناخية والبشرية

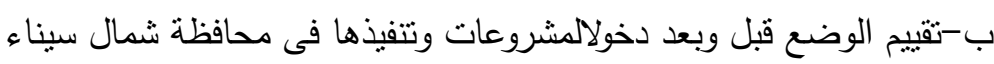

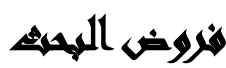

1-الفرض الأول: لا يوجد تأثير معنوي ذو دلالة إحصائية لأبعاد التغيرات المناخية (الأمطار - الرطوبة - درجات الحرارة) على الإثتاجية المحصولية فى محافظة شمال

r-الفرض الثانى: لا يوجد تأثثر معنوي ذو دلالة إحصائية للثقنيات المستخدمة بالمشروعات على الإنتاجية المحصولية فى محافظة شمال سيناء.

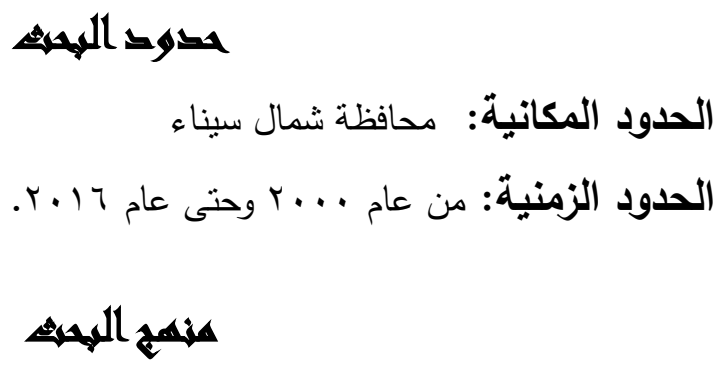

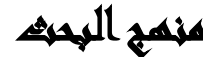

اعتمد البحث علي استخدام المنهج الوصفى التحليلى لعرض وتحليل مشكلة البحث

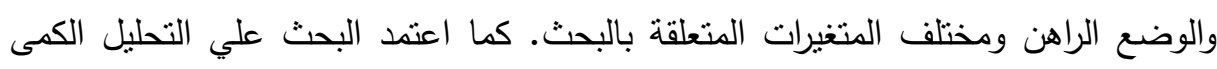
لقياس مدى استدامة المشروعات القائمة وقدرتها على تحقيق اهدافها من خلال الأساليب

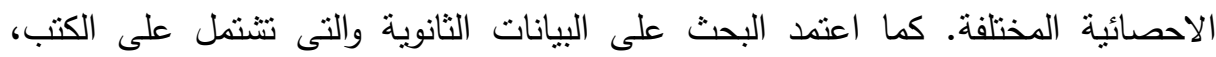

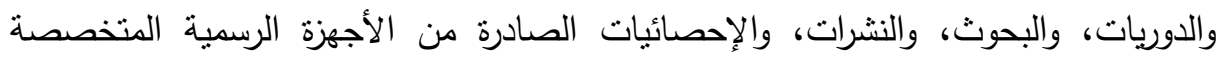


والتقارير السنوية والنصف سنوية الصادرة من المشروعات، وكما اعتمد البحث على البيانات الأولية والتنتشتمل عينة الدراسة والخاصة بالمشروعات القائمة بمحافظة شمال سيناء.

\section{أهمية المهمه}

تبرز أهمية البحث من كونه يتتاول موضوع تأثير التغيرات المناخية على الإنتاج

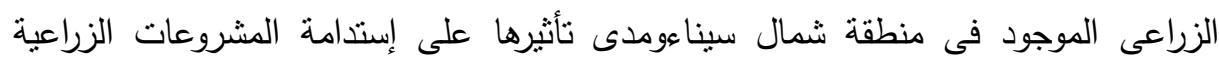

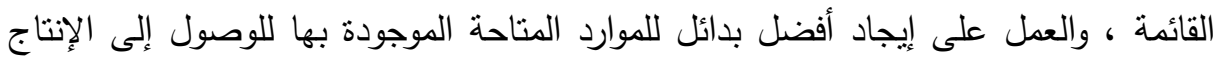
الزراعى الأمنل لتحقيق أقصى عائد أقتصادى ممكن.

\section{المسطلماهي اللرئمسيه:}

1. مفهوم التغيرات المناخية: عبارة عن اختلال فى الظروف المناخية المعتادة كالحرارة وأنماط الرياح والمنساقطات التى تميز كل منطقة على الأرض. عندما نتحدث عن تغير

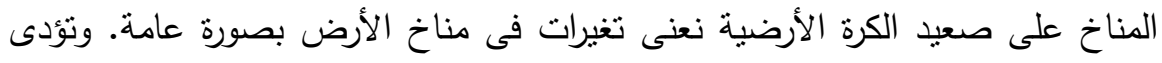

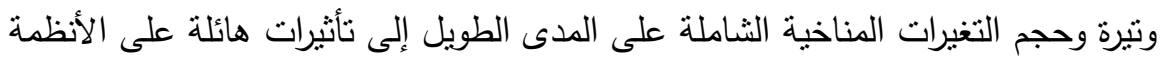

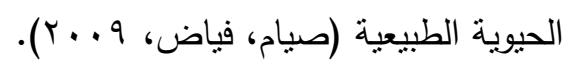

r . مفهوم الإستدامة: تعرف بإنها دراسة كيفية عمل الانظمة الطبيعية، والتتوع وإنتاج كل

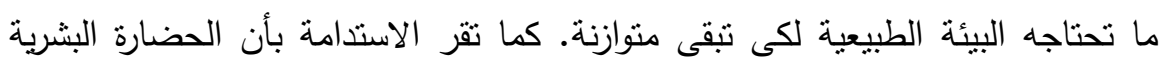

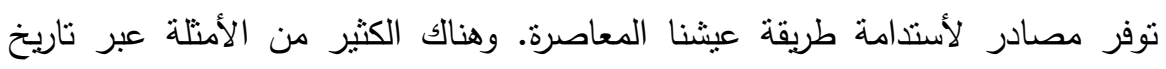
البشرية حيث عملت الحضارات على تدمير بيئتها وأثرت بشكل خطير على فرص البقاء البقاء.

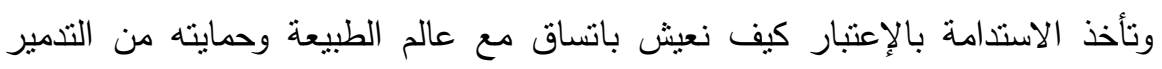

$$
\text { والإتلاف (الخواجة، } 7 \text { ( • ب). }
$$

r. مفهوم الإستدامة الزراعية: نظام منكامل من الممارسات الإنتاجية النباتية والحيوانية التى لها تطبيقات ميدانية خاصة تستمر على مدار فترة طويلة (2001،..- Lopez)

.Ridauraet al

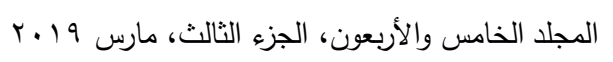


ـ ـ مفهوم الأراضي الحرجة: هى الأرض التى شهدت تدهور فى وظائفها الحيوية حتى مستوى معين وذلك بسبب أضرار قد لحقت بهاوتلك الوظائف هى الارضى وظائفها الأنتاجية

$$
\text { ونظام المياه(Prasetyo, et al،2013). }
$$

هـ مفهوم الأراضي الهامشية: هى الأراضى ذات القيمة الزراعية الضئيلة تتطلب

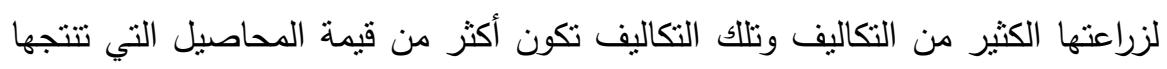

تلك الأراضى(Baumol and Blinder،2013) - كما تعرف بأنها الأراضى القاحلة عموماً، وعادة ما تكون لها إمكانيات محدودة أو معدومة

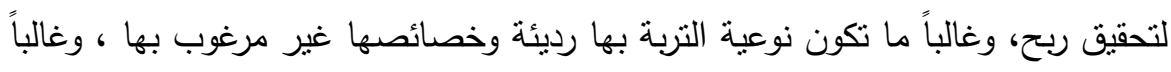

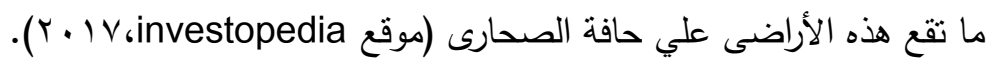

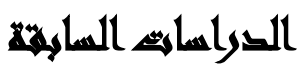

أولاً: مقدمة: أثتتت الدراسات العلمية أن المناخ يتغير حيث شهدت الأرض عبر تاريخها الطويل تغيرات مناخية كبيرة حيث تتابعت عليها العصور المختلفة كالعصر الجليدى والفترات

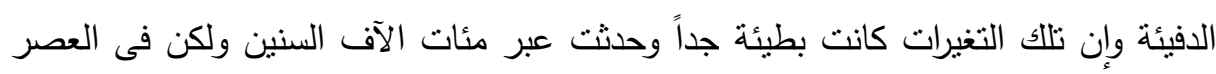

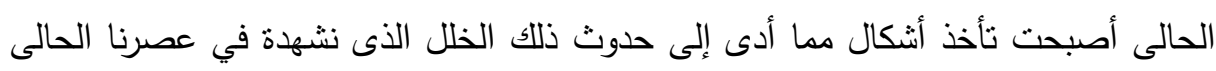

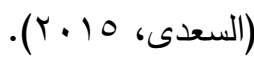

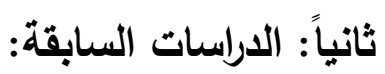
• دراسة (Mansour , 2017): هدفت الدراسة إلي تقييم آثنار تغير المناخ علي إنتاجية المحاصيل المختلفة بمحافظة شمال سيناء وكيفية تحسين تخصيص الموارد التى تناعد

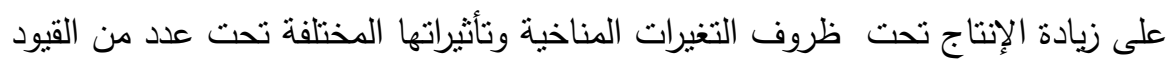
والتى تمنل قيود الرقعة الزراعية، حجم العمالة، كمية المياه المستخدمة، رأس المال المتاح،

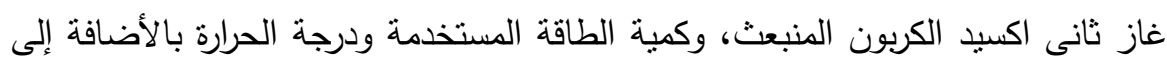

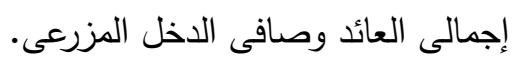


كما توصلت الدراسة إلي أنه فى ظل التركيب المحصولى الحالى لا يمكن تحقيق التوازن بين الأحتياجات الغذائية وزراعة المحاصيل الرئيسية ، الأمر الذى أدى إلى إلى زيادة

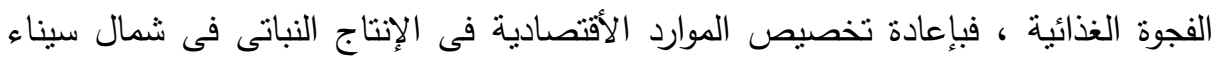

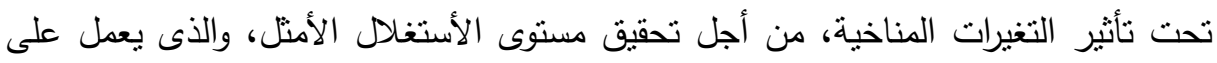

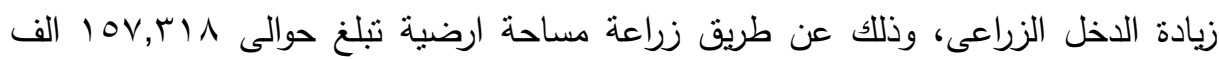

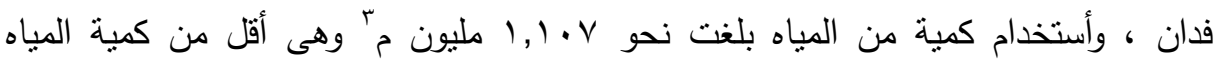

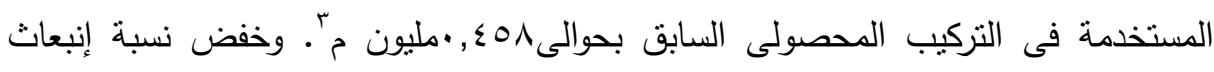

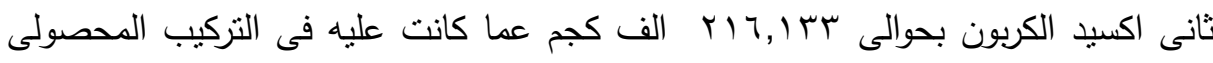

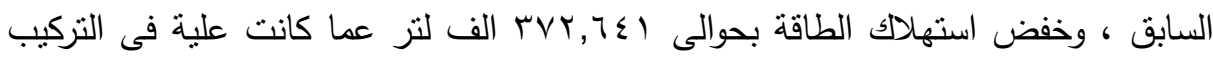
السابق. • دراسة (ICBA and DRC,2015): هدفت الدراسة لنظوير نظم إنتاج وإدارة أكثر مرونة وأكثر ملاعمة للظروف الاجتماعية والاقتصادية والبيئية في شمال سيناء ، وذلك

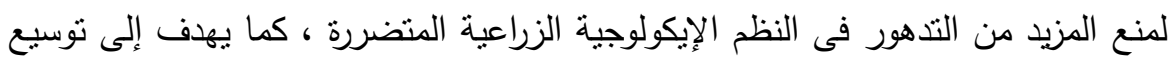
نطاق نموذج إنتاج البذور من الأنماط الجينية التي نم تحديدها بالفعل والتي تتحمل الإنه الملوحة . لماف.

وتوصلت الدراسة إلى أن بذور الأصناف المعدلة والأنواع الجينية المتحملة للملوحة ليست متاحة تجاريا، ولا تتتج الهيئات المتخصصة سوى عدد محدود من المحاصيل الاستراتيجية

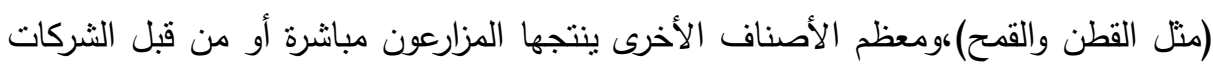
التجارية الذين لا يستطيعون الوصول إلى الأنماط الجينية المحسنة.

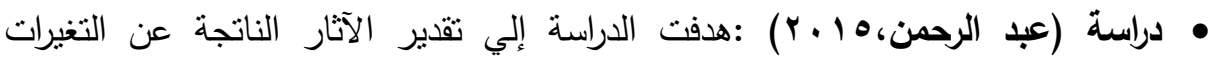

$$
\text { المناخية علي التركيب المحصولي بمصر . }
$$

وتوصلت الدراسة إلي أنه لا يتحقق التوازن فى ظل التركيب المحصولى الحالى بين الأحتياجات الغذائية والناتج المحلى للعديد من المحاصيل ، كما أنه حدث زيادة لأنهائ للفجوة الغذائية للمحاصيل الإستراتيجية الهامة وزيادة إستيراد الغذاء ، مما أدى إلى زيادة العجز في العيل الميزان

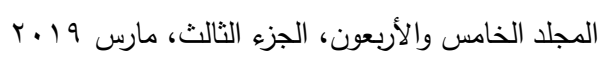


التجارى الزراعى نتيجة زيادة الفجوة الغذائية ، وقد أدت ظاهرة الأحتباس الحرارى والناجمة عن

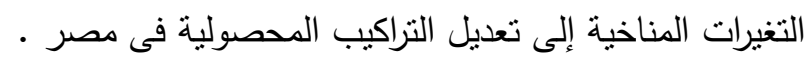

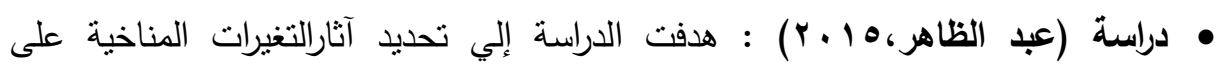

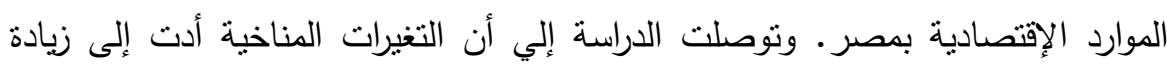

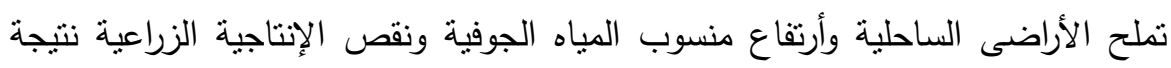

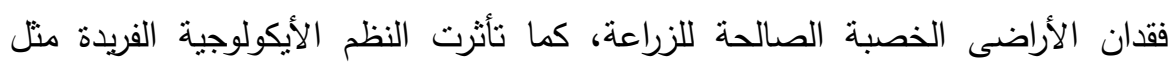
أشجار المانجروف الإستوائية فى البحر الأحمر.

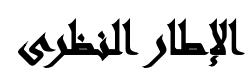

تتميز محافظة شمال سيناعبتوافر الموارد الأرضية المستصلحة والقابلة للاستصلاح والصالحة للزراعة، وتوفر مياه الرى سواء المياه الجوفية، أو مياه الأمطار أو من خلال

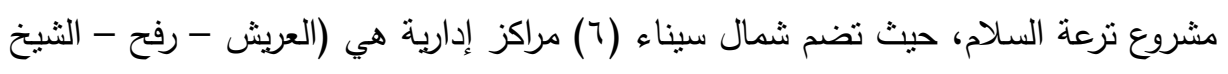

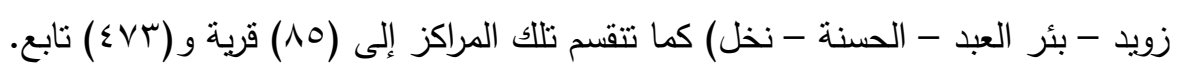

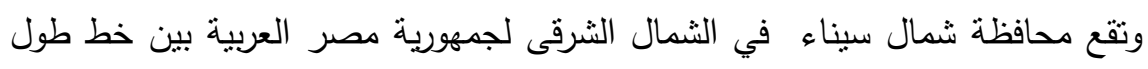

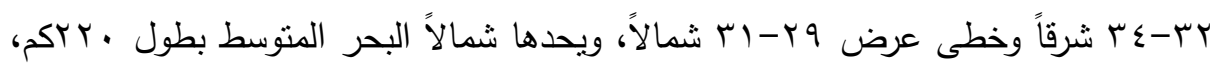

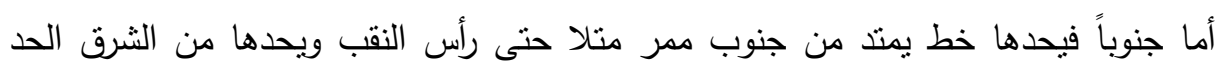

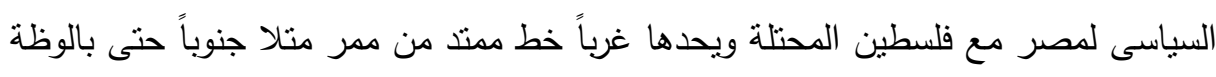

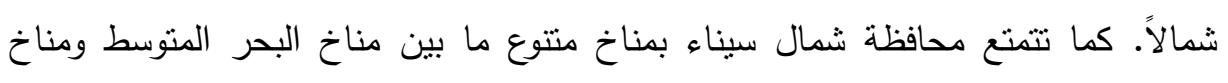

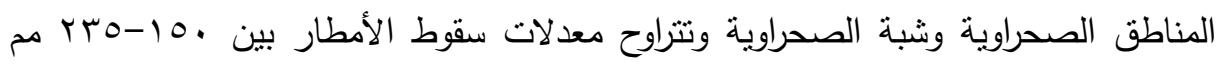

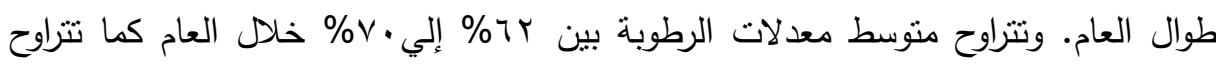

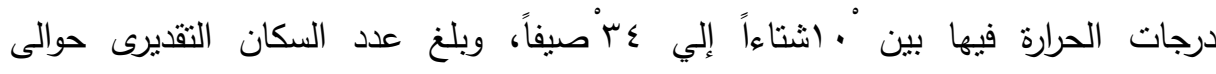

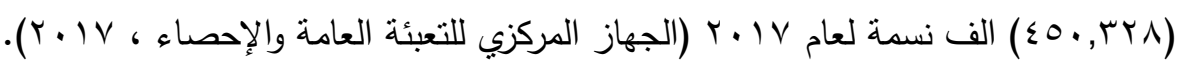

\section{السراسم التحليلية}

الإسلوب المنهجي: اعتمد البحث علي أسلوبان للحصول على البيانات الاحصائية

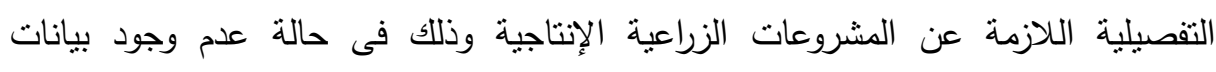
320

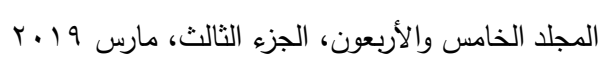


تفيلية يمكن الاعتماد عليها من خلال المصادر الرسمية المنشورة أو غير المنشورة وهما

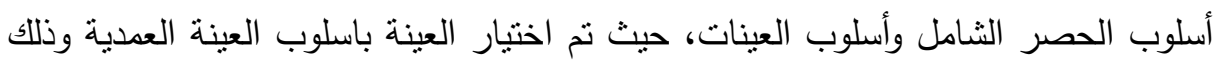
لتقييم بعض المشروعات الزراعية ذات الصلة بالتغيرات المناخية فى منطقة شمال سيناء

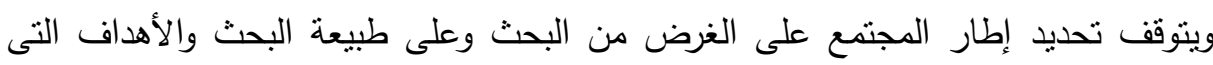

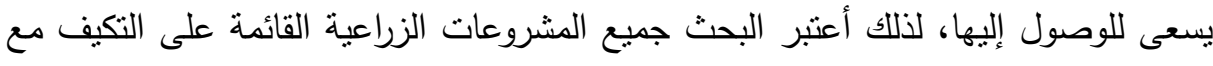
ظاهرة التغيرات المناخية بمحافظة شمال سيناء هى المجتمع وكذلك اعنبر أن إنتاج المحاصيل بأراضى المزارعين المشاركون بتلك المشروعات هى وحدة المعاينة. لذا فقد نم إجراء الدراسة الميدانية على المزارعين المستفدين منشروع (التكيف مع ظاهرة التغير المناخي فى البيئات الهامشية لمنطقة غرب آسيا وشمال أفريقيا من خلال التتوع المستدام للمحاصيل والثروة الحيوانبة) وعددهم كما في الجدول (1). جدول (1): عدد المزارعين الحائزين والمشاركين فى مشروع ( التكيف مع ظاهرة التغير المناخي في البيئات الهامشية لمنطقة غرب وشمال أفريقيا من خلال التنوع

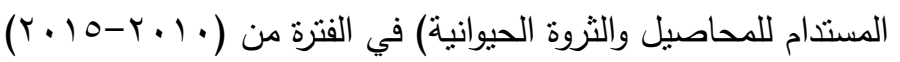

\begin{tabular}{|c|c|c|c|}
\hline عدد المشاركين & عدد الحائزين & القرية & م \\
\hline 11 & $\varepsilon \cdot 7$ & قرية ع & 1 \\
\hline $1 \leq \varepsilon$ & TrT & قرية 7 &.$r$ \\
\hline 17. & $\varepsilon 09$ & قرية V V V &.$r$ \\
\hline$\varepsilon \wedge \varepsilon$ & $119 V$ & الإجمالي & \\
\hline
\end{tabular}

المصدر : بيانات تقرير مشروع التكيف مع ظاهرة التغير المناخى في البيئات الهامشية. 


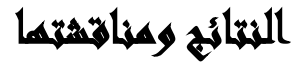

أولاً : تأثير التغيرات المناخية علي إنتاجية المحاصيل بثمال سيناء:

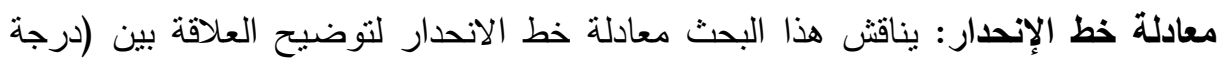

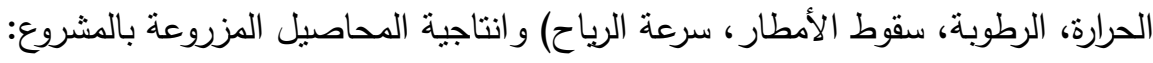

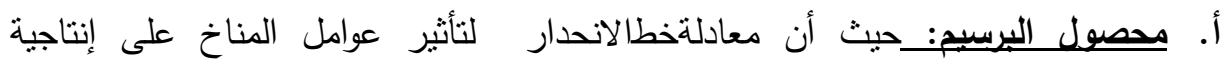
$\mathrm{Y}=85.066+0.544 \mathrm{X}_{1}-0.523 \mathrm{X}_{2}-0.637 \mathrm{X}_{3}-3.613 \mathrm{X}_{4}$

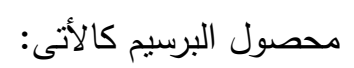
$\begin{array}{llll}(0.589) \quad(-0.418) \quad(-0.297) \quad(-0.619) & 0\end{array}$ $\mathrm{R}^{2}=0.151 \quad \mathrm{~F}=0.533$

$$
\text { حيث Y، تعني الإنتاجية (وهي متغير تابع) }
$$

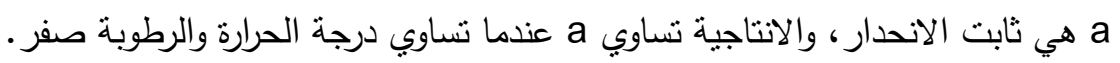
يمثل معدل سقوط الأمطار (وهى متغير مستقل)

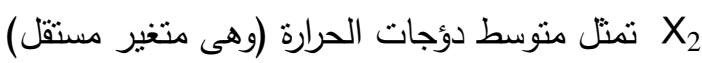

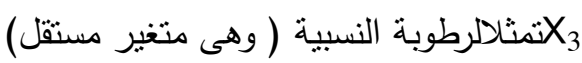

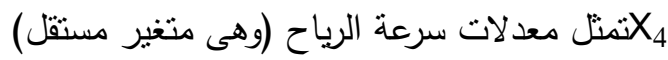
تأثيرسقوط الأمطار ودرجة الحرارة والرطوبة النسبية والرياح على الإنتاجية بدراسة معادلة خط الانحدار يتضح أن القيم التتبؤية لتأثثر سقوط الأمطار على

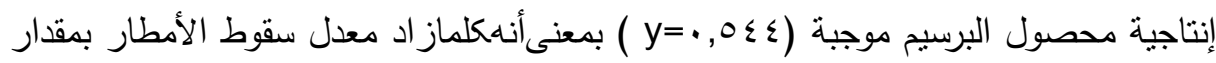

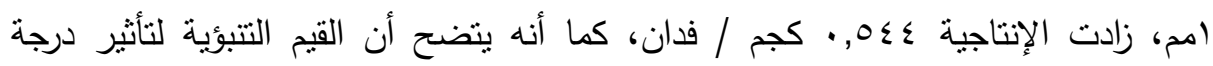

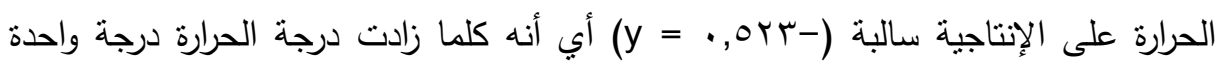

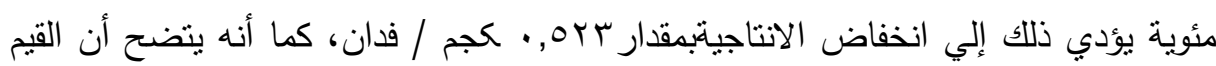

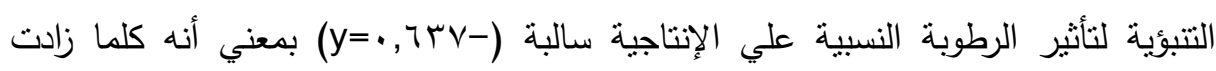

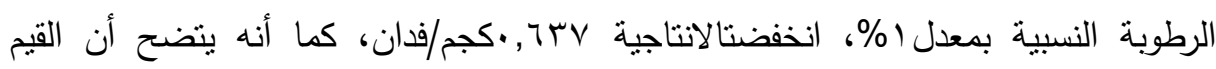

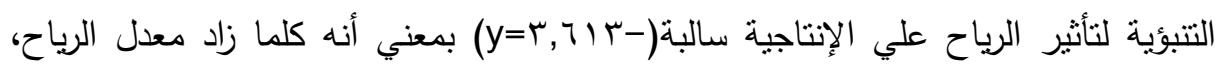

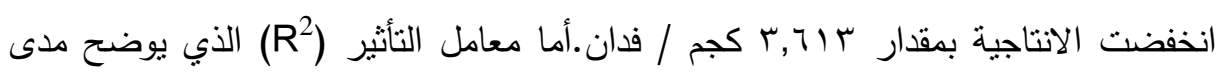


تأثثر معدل سقوط الأمطار ودرجة الحرارة والرطوبة النسبية ومعدل الرياح (عوامل المناخ)

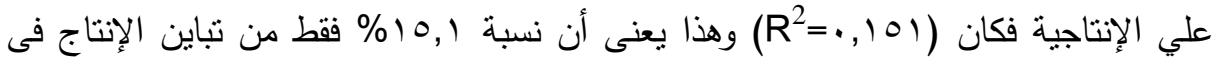

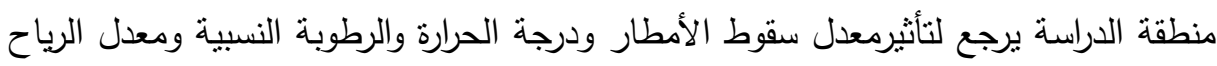

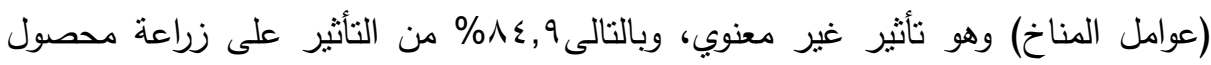

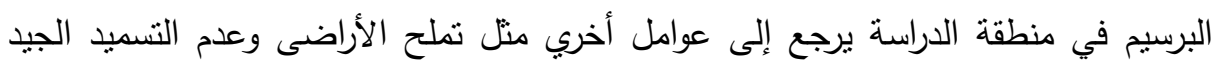
للأرض و نقص كمية التقاوى المفروض استخدامها للحصول على الأنتاج الأمنل نظراً لزيادة الاسعار بسبب ارتفاع أسعار العمالة.

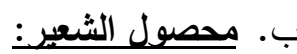

حيث أن معادلة خط الانحدار لتأثير عوامل المناخ على إنتاجية محصول الثعير كالأتى: $\mathrm{Y}=9.76+0.097 \mathrm{X}_{1}-0.18 \mathrm{X}_{2}+0.118 \mathrm{X}_{3}-0.112 \mathrm{X}_{4}$

$(1.17) \quad(-3.16) \quad(2.49) \quad(-0.33)$

$\mathrm{R}^{2}=0.528 \quad \mathrm{~F}=4.84 *$

يتضح أن القيم التتبؤية لتاثير سقوط الأمطارعلى انتاجية محصول الثعير

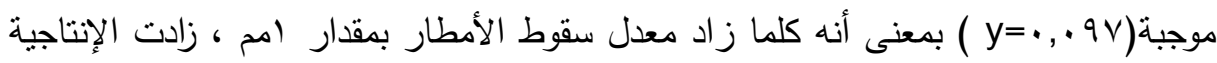

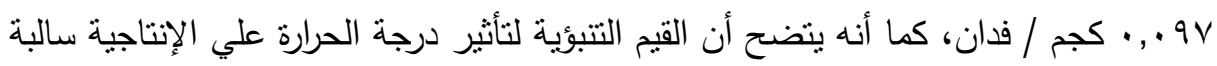

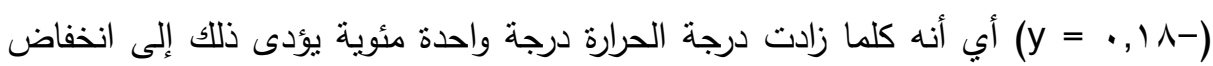

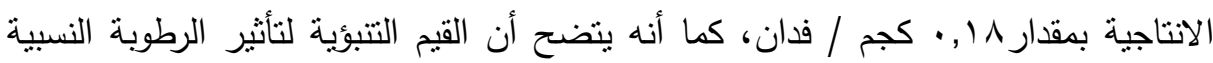

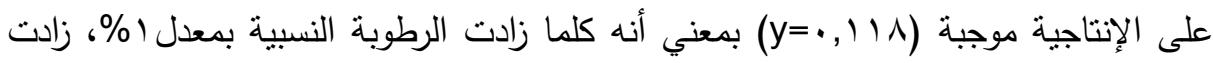

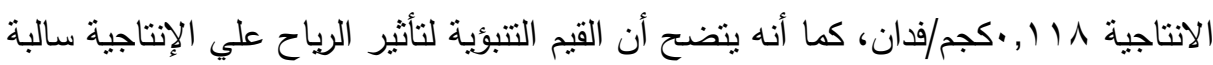

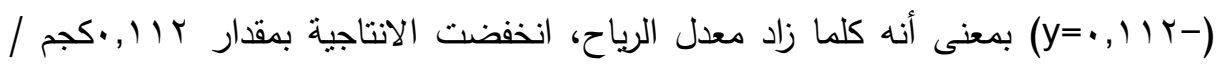
فدان. أما معامل النأثثر (R2) الذي يوضح مدى تأثنيرمعدل سقوط الأمطار ودرجة الحرارة

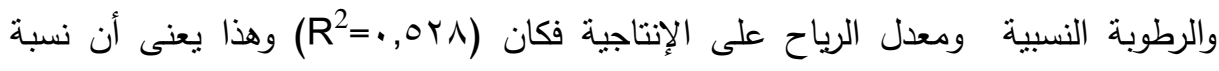

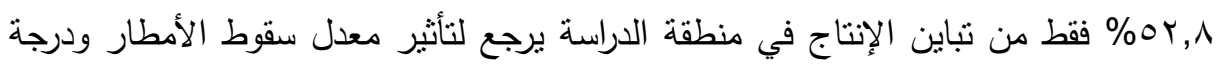

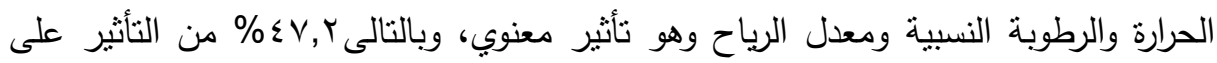
زراعة محصول الثعير في منطقة الدراسة يرجع إلي عوامل أخرنتم ذكرها سابقا.

$$
\text { المجلد الخامس والأربعون، الجزء الثالث، مارس } 19 \text { ب ب ا }
$$


ج. محصول بنجر العلف: حيث أن معادلة خط الانحدار لتأثير عوامل المناخ علي إنتاجية

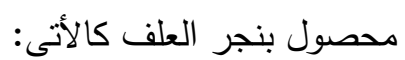

$\mathrm{Y}=-114.53-0.022 \mathrm{X}_{1}+4.900 \mathrm{X}_{2}+0.861 \mathrm{X}_{3}-3.857 \mathrm{X}_{4}$

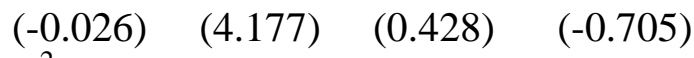

$\mathrm{R}^{2}=0.628 \quad \mathrm{~F}=5.529 * *$

يتضح أن القيم التتبؤية لناثير سقوط الأمطارعلى إنتاجية محصول بنجر العلف

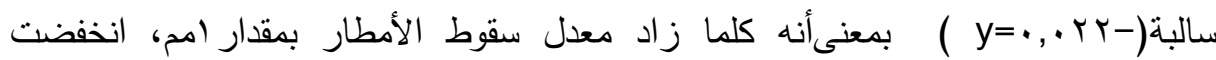

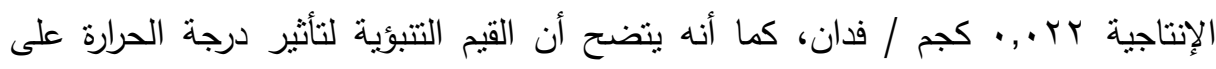

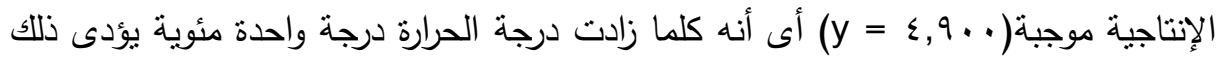

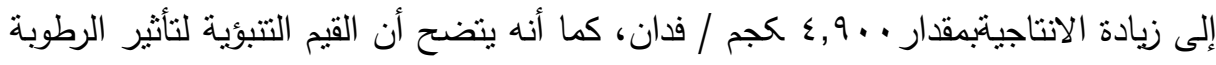

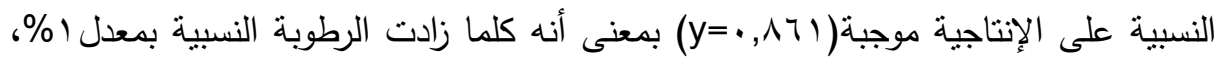

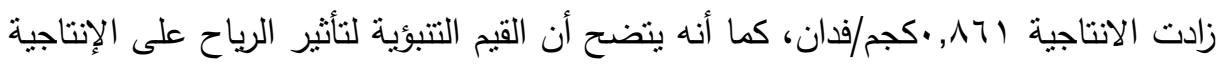

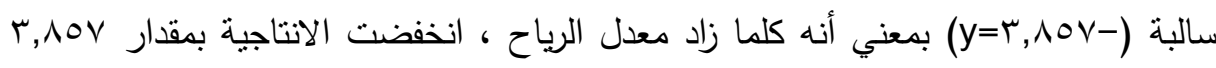

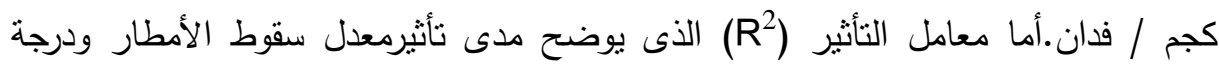

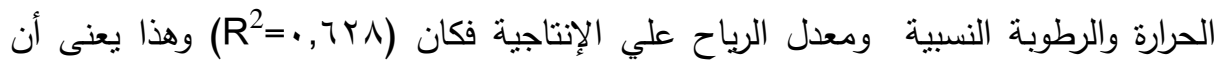

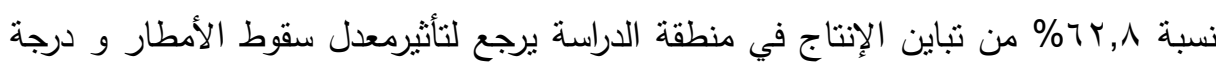

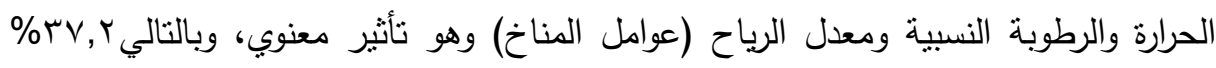
من الثأثير على زراعة محصول بنجر العلف فيى منطقة الدراسة برجع إلى عواملأخري بيئية وبثرية. د. مصصول الاخن: حيث أن معادلةخطالانحدارلنأثير عوامل المناخ على إنتاجية محصول $\mathrm{Y}=-418.95+3.419 \mathrm{X}_{1}+1.818 \mathrm{X}_{2}+5.658 \mathrm{X}_{3}+6.148 \mathrm{X}_{4}$

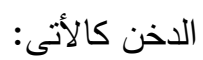

$\begin{array}{llll}(0.062) & (0.092) \quad(0.154) & (0.826)\end{array}$

$\mathrm{R}^{2}=0.204 \quad \mathrm{~F}=0.77$

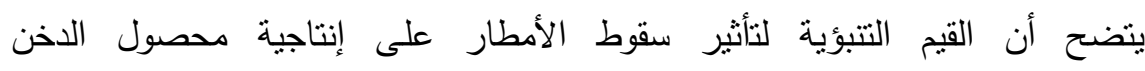

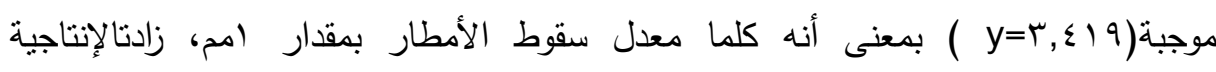

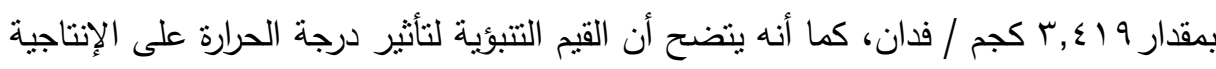

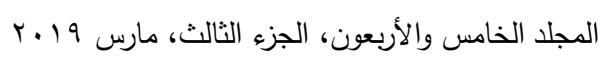


موجبة (1) (y=1,^) أي أنه كلما زادت درجة الحرارة درجة واحدة مئوية يؤدي ذلك إلي زيادة

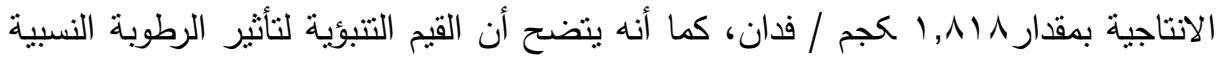

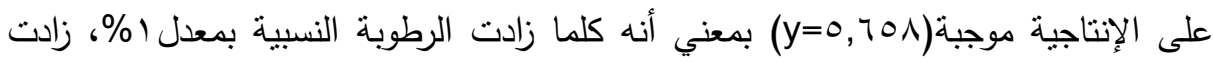

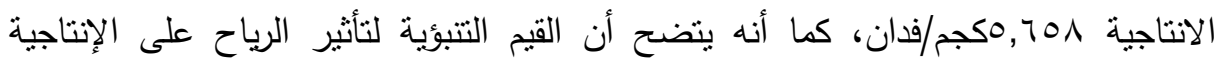

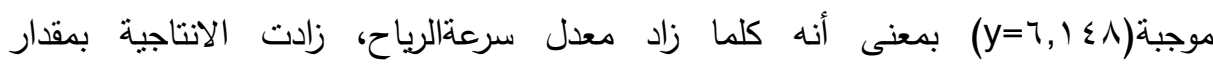

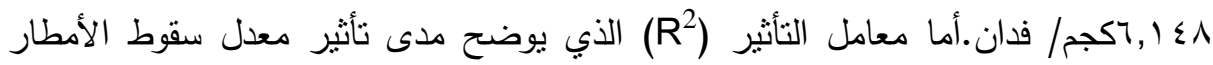

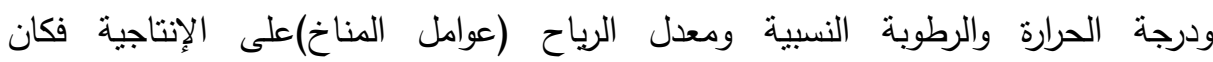

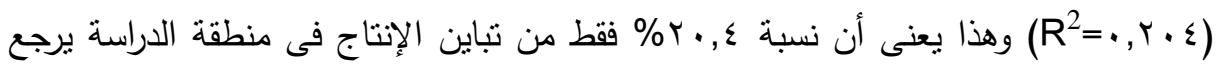

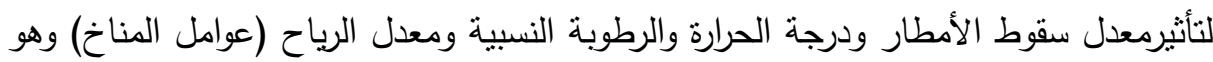

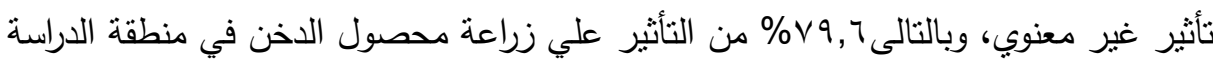
يرجع إلي عوامل أخربيئية وبشرية.

هـ -محصول السورج: حيث أن معادلةخطالانحدارلتأثثر عوامل المناخ على إنتاجية

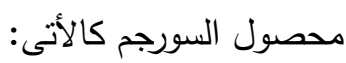
$\mathrm{Y}=1959.39+37.719 \mathrm{X}_{1}+1.493 \mathrm{X}_{2}-28.471 \mathrm{X}_{3}-1.624 \mathrm{X}_{4}$ $\begin{array}{llll}(1.812) & (0.200) \quad(-1.998) & (-0.561)\end{array}$ $\mathrm{R}^{2}=0.390 \quad \mathrm{~F}=1.919$ بدراسة معادلة خط الانحدار يتضح أن القيم التنبؤية لتأثير سقوط الأمطار على إنتاجية

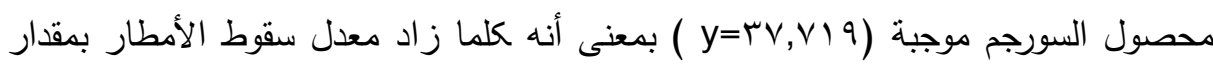

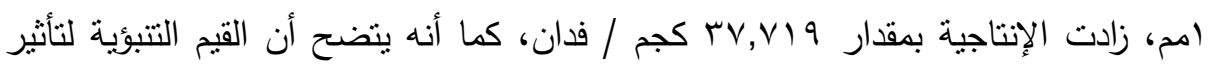

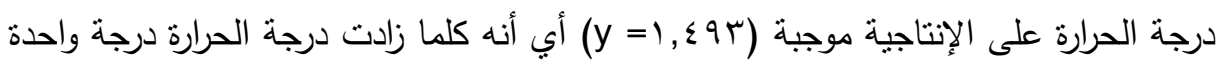

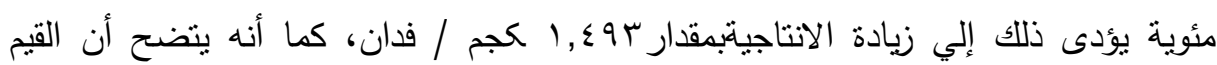

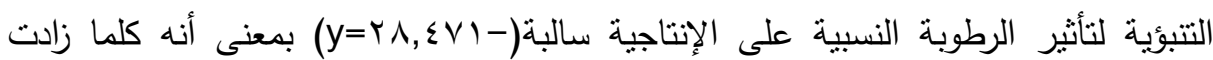

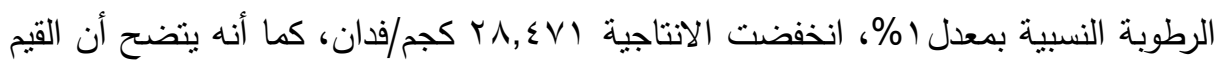

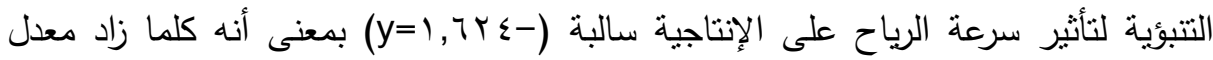

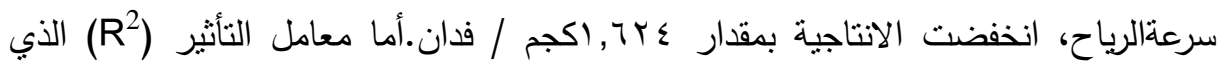

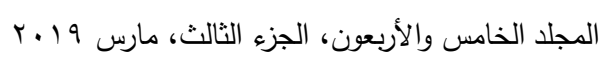


يوضح مدى تأثثرمعدل سقوط الأمطار ودرجة الحرارة والرطوبة النسبية ومعدل الرياح على الأى

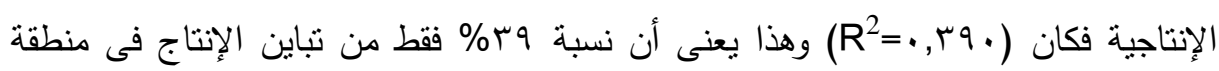
الدراسة يرجع لتأثثر معدل سقوط الأمطار ودرجة الحرارة والرطوبة النسبية ومعدل الرياح

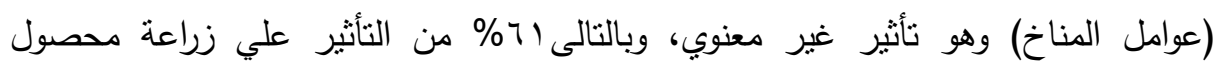
السورجم فى منطقة الدراسة يرجع إلى عوامل أخرى بيئية وبشرية.

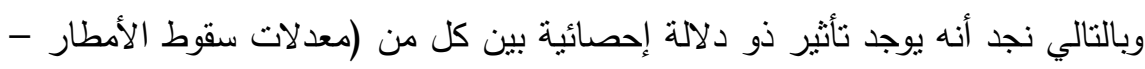

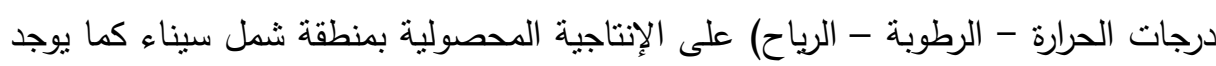

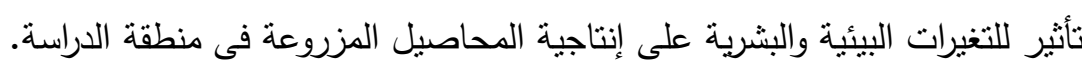
ثانياً: التقيم الاقتصادي للمشروعات:

1-تقييم الأثر الاقتصادي لمشروع التكيف مع ظاهرة التغير المناخي في البيئات الهامشية لمنطقة غرب آسيا وشمال أفريقيا من خلال التنوع المستدام للمحاصيل والثروة

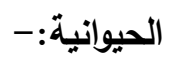
يتضمن التقييم تقدير الإنتاجية وإجمالي التكاليف وإجمالى الإيرادات، وتحليل إجمالي هامش الربح ومعادلة إتجاه الوقت والكفاءة الإنتاجية لكل محصول قبل وخلئل وخلال فترة المشروع. وتم تقدير جميع الأسعار وفقاً لأسعار السوق لكل موسم. يشمل إجمالي التكاليف المتغيرة كل من تحضير الأرض للزراعة والتقاوي والري و التسميد وخدمة المحصول و مقاومة الأفات

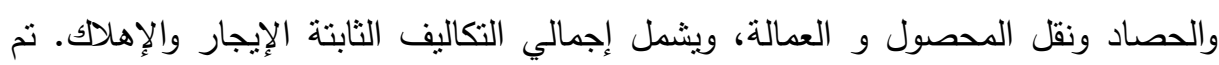
تثبيت الأجور عند ـ0 جنيه للفرد يومياً لكل المهام.

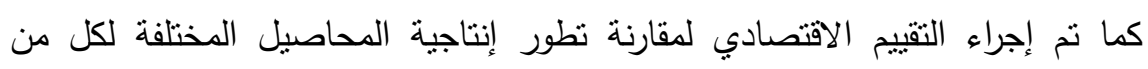
الممارسات الزراعية التقليدية التي كانت تستخدم قبل بدء أنشظة المشروع في المنطقة والممارسات الزراعية المحسنة بعد بدء أنشطة المشروع لخمسة محاصيل متتوعة

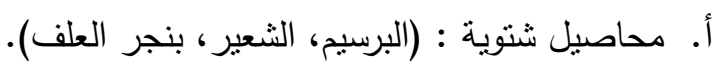
ب. محاصيل صيفية : (الدخن، السورجم). 


\section{أولاً : مؤثرات الكفاءة للمحاصيل الثتوية:}

1-محصول الميرسيح

جدول (ץ): مؤشرات الكفاءة الإنتاجية والاقتصادية لمحصول البرسيم باستخدام الممارسات

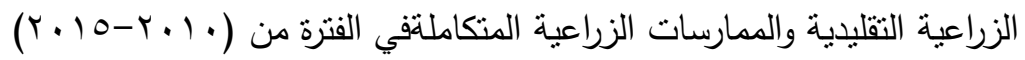

\begin{tabular}{|c|c|c|c|c|c|c|}
\hline الجنائدية على & الإليراداتة & (جنية/فالريح) & 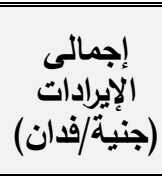 & (التكاليف & الانتاجية & \\
\hline$\cdot, 79$ & 1,79 & $1 \vee \wedge 9$ & $\sum T \wedge Y$ & roqr & r & تقليدية \\
\hline 1,11 & $r, 1 \wedge$ & TTYY & $\sum \wedge 01$ & KYYT & $r V, Y O$ & منكارملة \\
\hline
\end{tabular}

المصدر: جمعت وحسبت من بيانات نقرير مشروع التكيف مع ظاهرة التغير المناخى في الفترة من

$$
\cdot(r \cdot 10-r \cdot 1 \cdot)
$$

تبين من التقييم الاقتصادى لإتتاجية محصول البرسيم قبل بدء المشروع ومع إستخدام

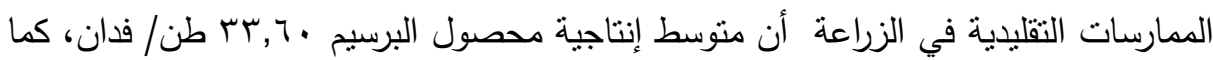

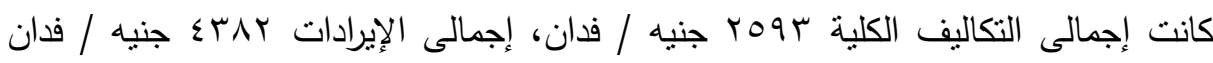

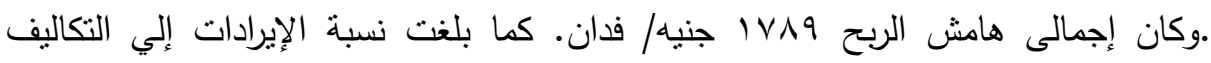

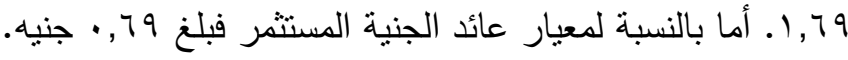

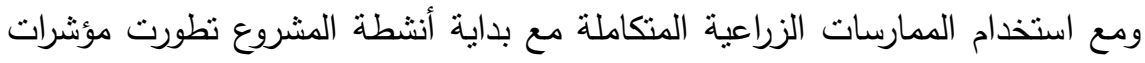

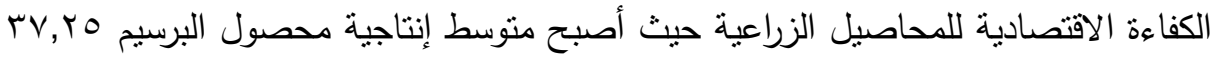

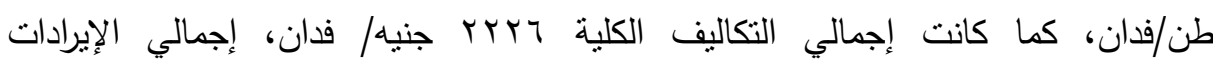

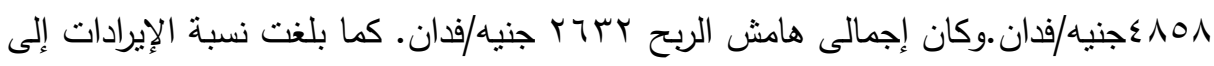

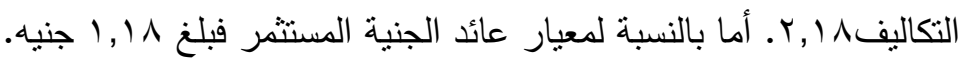


جدول (ץ): مؤشرات الكفاءة الإنتاجية والاقتصادية لمحصول الثعير بإستخدام الممارسات

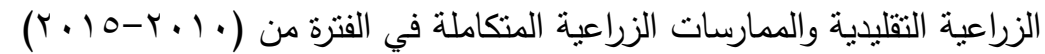

\begin{tabular}{|c|c|c|c|c|c|c|c|}
\hline الجنية المبائد & الإليرادات & (جنية/فالران) & (إجنيراداتي & الكلية & متانتاج & 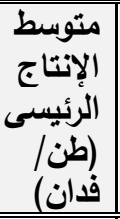 & \\
\hline$\cdot, 0 \leqslant$ & $1,0 \leq$ & $V .0$ & $r \ldots$ & $1 Y 90$ & $1, r_{0}$ & Y,,. & تقليدية \\
\hline$\cdot, \vee \diamond$ & $1, v 0$ & I YAV & $\mu \ldots$ & $1 v 1 r$ & 1,0 & $Y, q \leq$ & متكارسلة \\
\hline
\end{tabular}

المصدر : جمعت وحسبت من بيانات ثقرير مشروع التكيف مع ظاهرة التغير المناخفي الفترة من $\cdot(r \cdot 10-r \cdot 1 \cdot)$

تبين من التقييم الاقتصادي لإنتاجية محصول الثعير قبل بدء المشروع ومع إستخدام

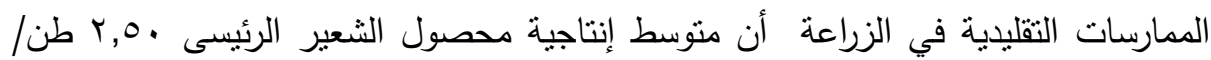

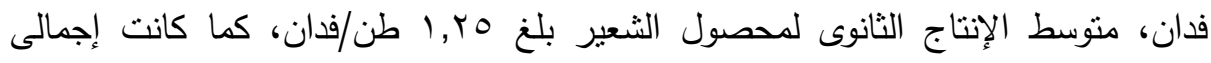

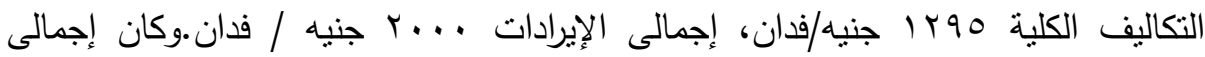

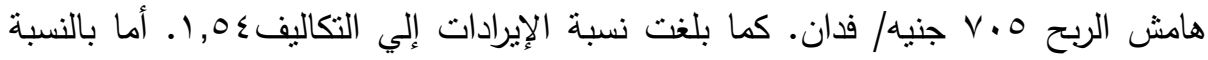
لمعيار عائد الجنية المستثر فبلغ عه, • جنيه. ومع إستخدام الممارسات الزراعية المتكاملة مع بداية أنشطة المشروع تطورت مؤشرات

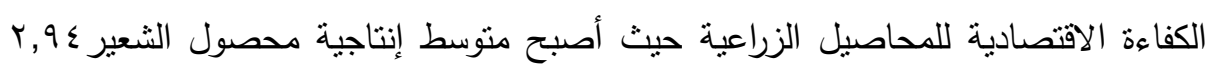

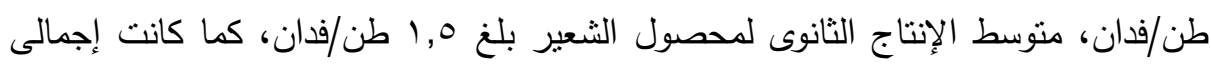

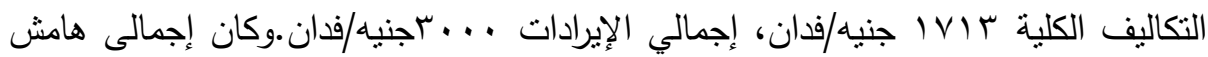

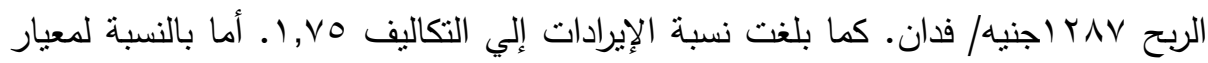
عائد الجنية المستثر فبلغ VO, •جنيه. 
r-محصول بنجر العلف:

جدول(؛): مؤشرات الكفاءة الإنتاجية والاقتصادية لمحصول بنجر العلف بإستخدام الممارسات

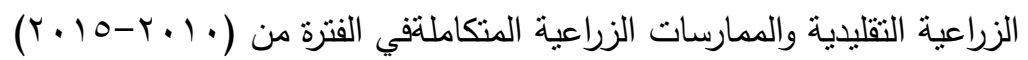

\begin{tabular}{|c|c|c|c|c|c|c|c|}
\hline الجنيّية & الإلترالية أليرات & (جنية/فيحان) & (جنيه/|فادان) & 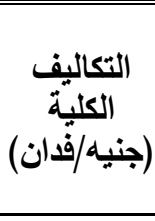 & الانتانتاج & الإنتاجسيس & \\
\hline תT & $1, \pi r$ & $r \cdot 9 \leq, r$ & $0 \leqslant 00,0$ & ז,ודזי & $\{, 00$ & ro, 10 & تقلبيدية \\
\hline$\cdot, \mathrm{V} 4$ & $1, \vee 7$ & YTVI,YO & Tr..,70 & roY $9, \varepsilon$ & $0, r \pi$ & 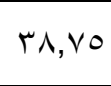 & متكارسلة \\
\hline
\end{tabular}

المصدر: جمعت وحسبت من بيانات تقرير مشروع التكيف مع ظاهرة التغير المناخفي الفترة

$$
\cdot(r \cdot 10-r \cdot 1 \cdot)
$$

تبين من التقييم الاقتصادي لإنتاجية محصول بنجر العلف قبل بدء المشروع ومع

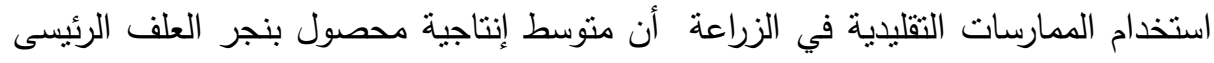

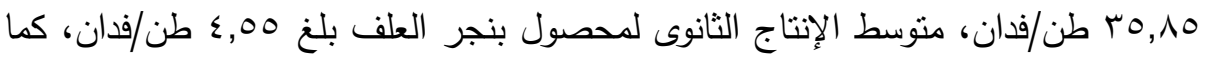

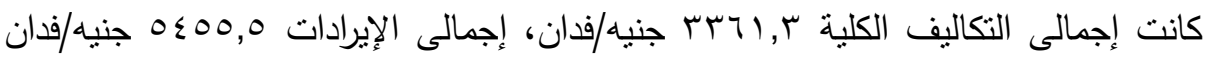

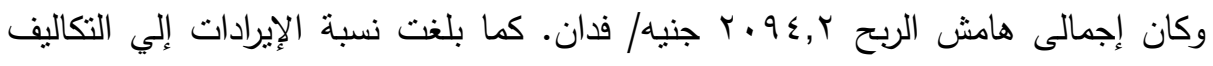

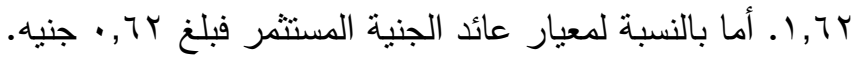

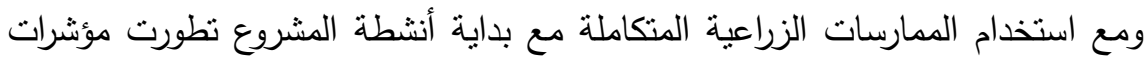

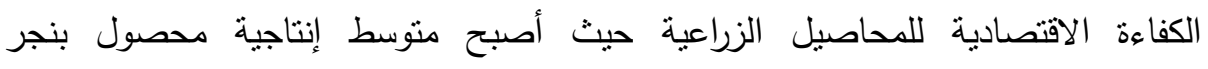

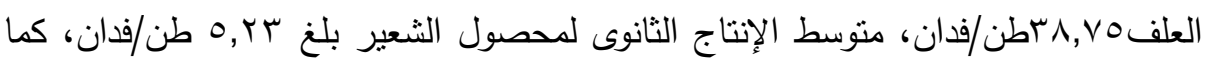

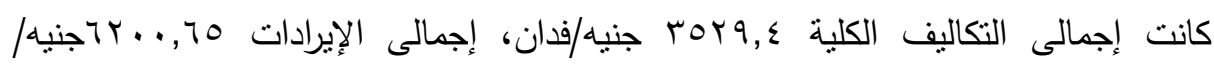

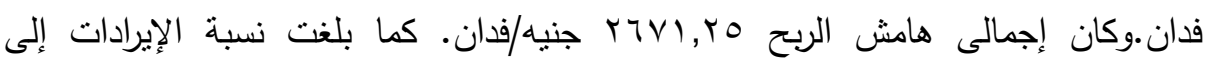

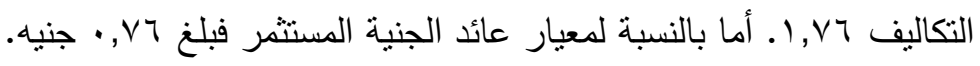




\section{ثُانباً : مؤثرات الكفاعة للمحاصيل الصبفية:}

ع - محصول (لدخن:

جدول(ه): مؤشرات الكفاءة الإنتاجية والاقتصادية لمحصول الدخن بإستخدام الممارسات

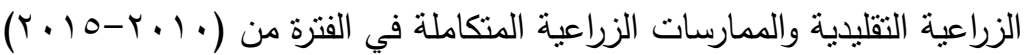

\begin{tabular}{|c|c|c|c|c|c|c|}
\hline 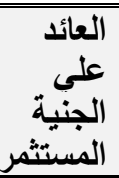 & الإلية الإداث & (جنية/فالرانح) & ألإيراداتي & (التكاتيف & الإنتائيسي & \\
\hline $1,0 \mathrm{~V}$ & $Y, O V$ & r.ov & $0 \ldots$ & $19 \leqslant r$ & זr, •0 & تقليدية \\
\hline$r, r$. & . & $\leqslant 91 \wedge$ & $V .0 \xi$ & דrוץ & or,tV & مثارساتة \\
\hline
\end{tabular}

المصدر : جمعت وحسبت من بيانات تقرير مشروع التكيف مع ظاهرة التغير المناخى في الفترة من $\cdot(r \cdot 10-r \cdot 1 \cdot)$

تبين من التقييم الاقتصادي لإنتاجية محصول الثعبر قبل بدء المشروع ومع إستخدام

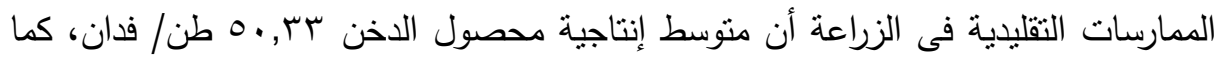
كانت إجمالى التكاليف الكلية س؟ 19 جنيه/فدان، إجمالى الإيرادات ... .0 جنيه/ فدان .وكان

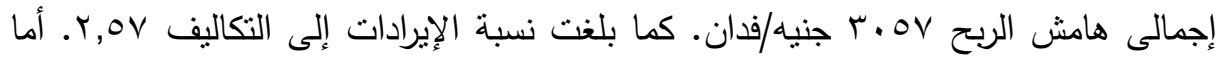

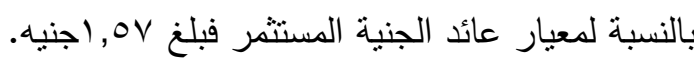
ومع استخدام الممارسات الزراعية المتكاملة مع بداية أنشطة المشروع تطورت مؤشرات الهيه

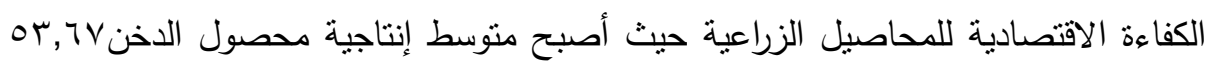
طن/فدان، كما كانت إجمالى التكاليف الكلية بrآبه جنيه/فدان، إجمالى الإيرادات

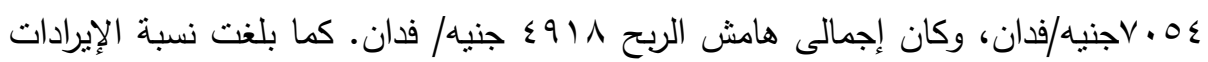

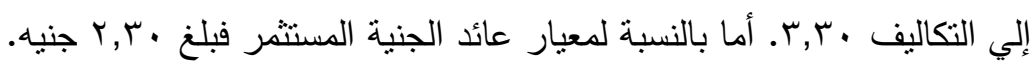


جدول (†): مؤشرات الكفاءة الإنتاجية والاقتصادية لمحصول السورجم بإستخدام الممارسات

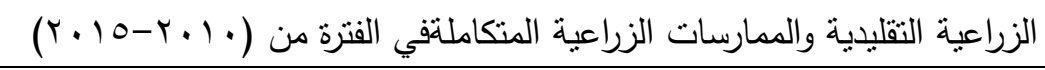

\begin{tabular}{|c|c|c|c|c|c|c|}
\hline الجنية & ألتبكية الإيرادات & (جنية/فالريح) & 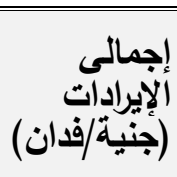 & (الكليةليفة & الأرئيستئي & \\
\hline$\cdot, 0$ & 1,0 & $\mid Y O \Lambda, \varepsilon$ & rᄉro,v & rOVV,r & $r v, \Lambda$ & تقلبدية \\
\hline$\cdot, \mathrm{V}$ & $1, V$ & $19 \ldots$ & $\sum V Y Y, 1$ & YAYY, & $0 ., Y \mu$ & مثكارسلة \\
\hline
\end{tabular}

المصدر : جمعت وحسبت من بيانات تقرير مشروع التكيف مع ظاهرة التغير المناخى في الفترة من

$$
\cdot(r \cdot 10-r \cdot 1 \cdot)
$$

تبين من التقييم الاقتصادي لإنتاجية محصول السورجم قبل بدء المشروع ومع إستخدام

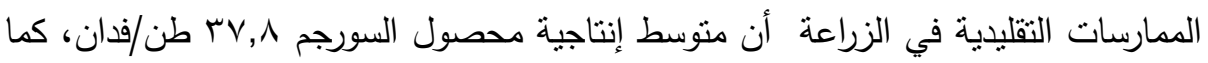

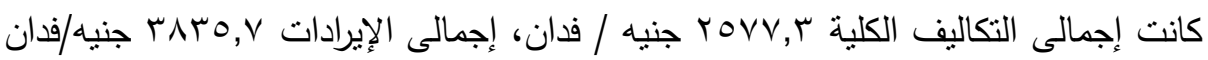

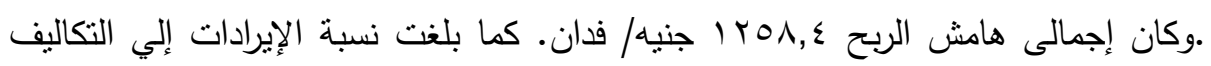

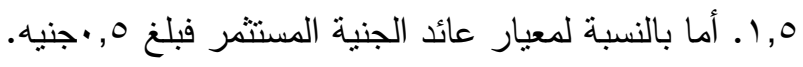

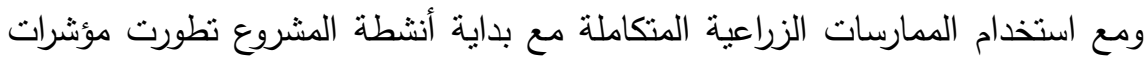

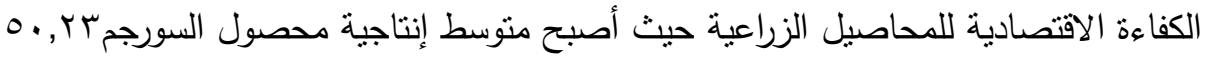

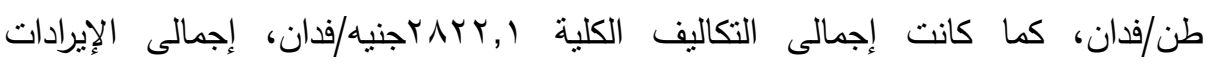

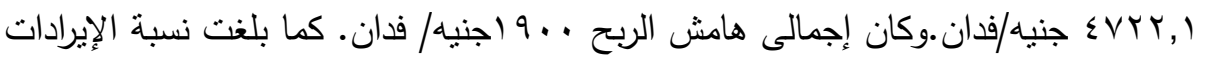

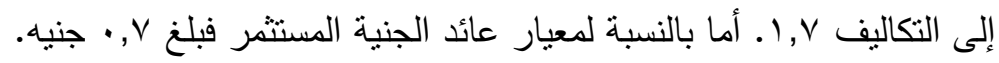
ويتضح من النتائج السابقة أنه نتيجة إستخدام الأساليب الزراعية الحديثة والتقنيات العلئية

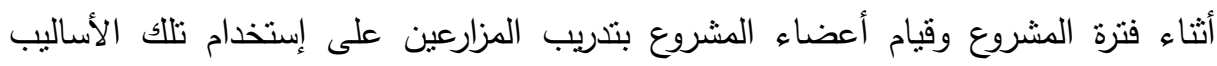

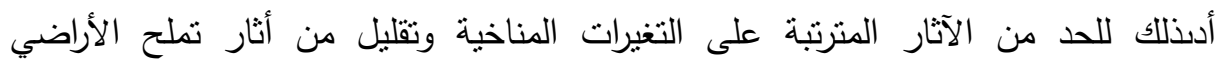

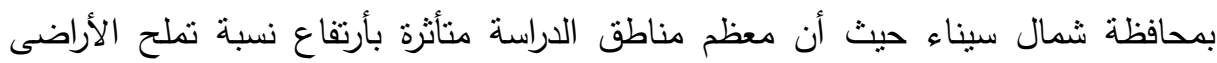


(مركز بحوث الصحراء ، ج . . ץ)،كما أدى إلنزيادة كل من الإنتاجية و الإيرادات وهامش

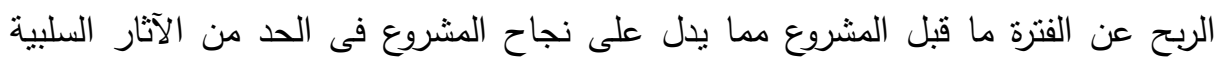
للتغيرات المناخية والقدرة علي التكيف مع تلك الظاهرة

\section{المهوبياهي}

1. تعميم الاساليب الزراعية الحديثة المستخدمة في المشروعات العاملة على التأقلم مع ظاهرة

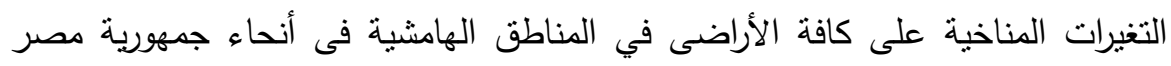

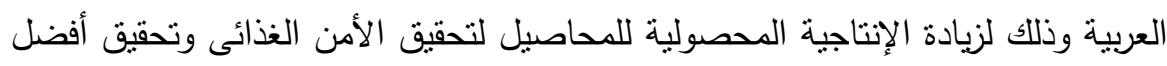

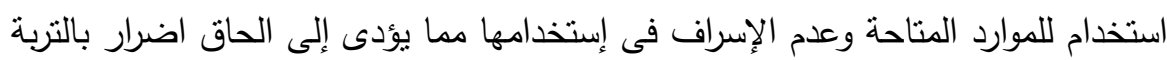

$$
\text { الزراعية مما يحدث تملح وبالتالى تصحر للأراضى. بوان. }
$$

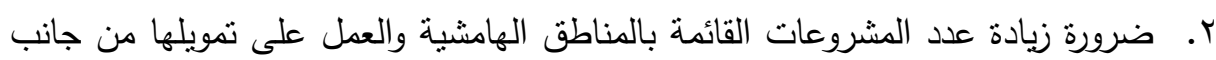

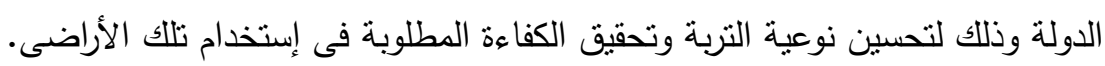

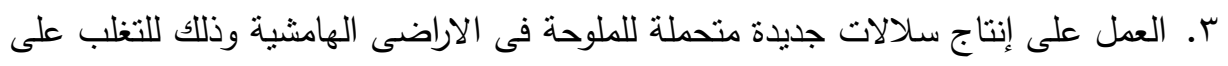

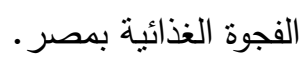

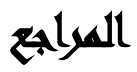

أحمد مصطفى خاطر(ب991). الإدارة وتقويم مشروعات الرعاية الاجتماعية، المكتب

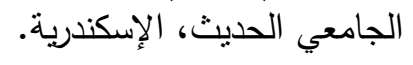

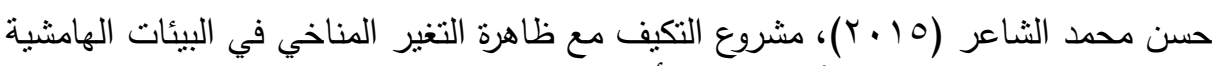

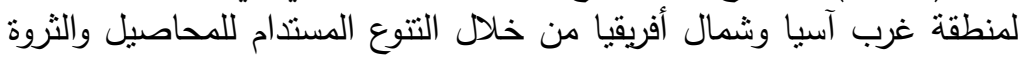

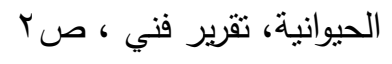

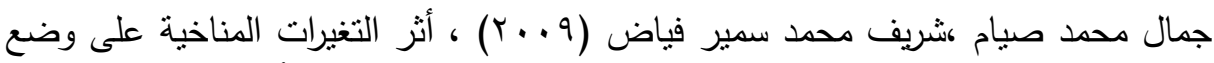

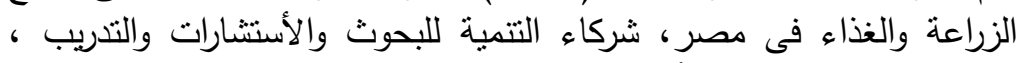

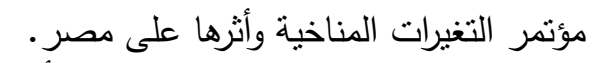

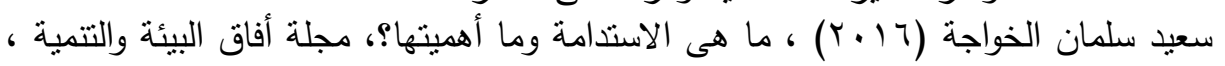

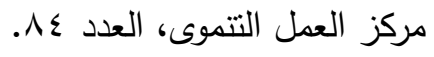

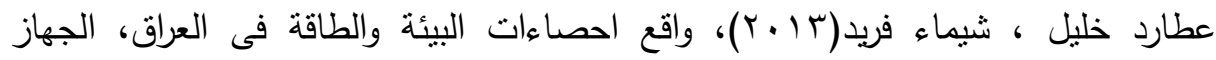

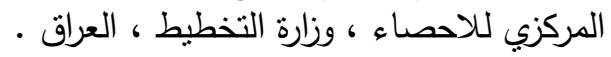

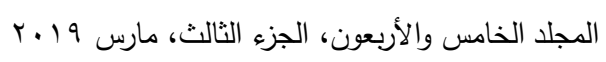




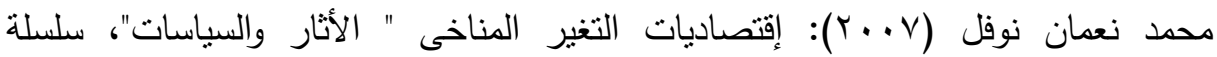

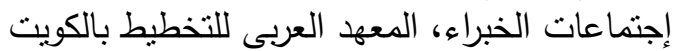

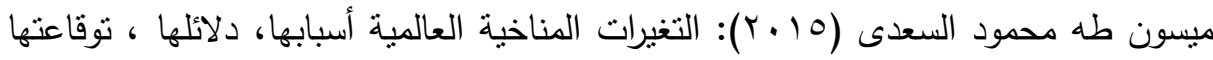

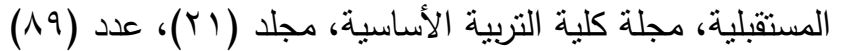

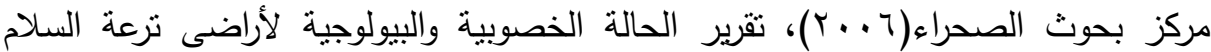

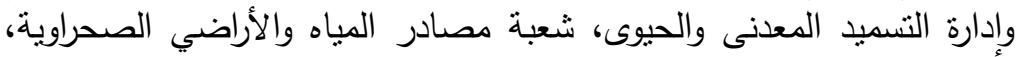

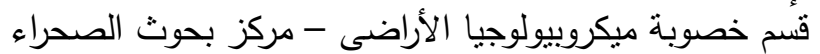

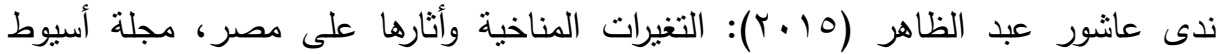

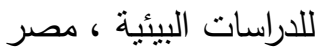

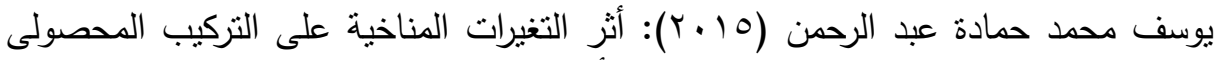

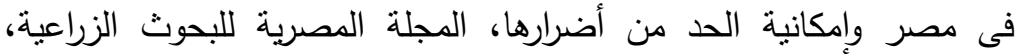

$$
\begin{aligned}
& \text { مصر }
\end{aligned}
$$

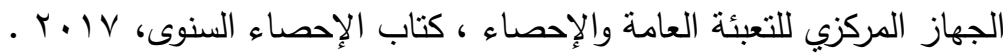

Prasetyo S.Y.J; Hasiholan,B; Hartomo,D,K;Paseleng,M (2013), Geographic Information System of Critical Level of Land Degradation (Critical Land) Based on Agro-ecological Zone (AEZ) in Agricultural Areas with Recombination Method of Fuzzy Logic and Scoring,International Journal of Computer Science Issues .Vol. 10, Issue 6, No1.

Pierce.J (1990), The Food Resources: Themes in Resources Management. London: Longman.

Lopez -Ridaura,S.;Keuler, H.V.;Vanittersum , M.K. and Lefelaar , P.A (.2005)" Multiscale methodological framework to derive criteria and indicators for Sustainability evaluation of peasant natural resources management systems " Environ Dev. Sustain. Vol 7.

Mansour ,S.F (2017),Assessment of the impact of climate change and the speed of adaptation in Egypt - (North Sinai case study), Imperial Journal of Interdisciplinary Research- V3, Issue-6.

Baumol,W;Blinder,A,(2011), Economics: Principles and Policy, Cengage learning, $12^{\text {th }}$ Edition

https://www.investopedia.com/terms/m/marginal-land.asp

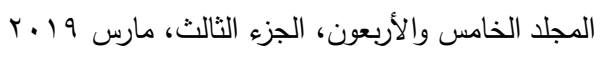


سليم محمد سليم علي دحدوح وآخرون

\title{
AN INVESTIGATIVE STUDY FOR ONE OF THE EMERGING PROJECTS IN THE NORTHERN REGION OF SINAI WITH ADAPTATION OF CLIMATE CHANGES
}

\author{
Sleem M. S. A. Dahdooh ${ }^{(1)}$; Mossad S. Ragab ${ }^{(2)}$ \\ Hesham I. ELKassas ${ }^{(3)}$ and Shereen F. Mansour ${ }^{(4)}$
}

1) High Institute of Computer and Management Information System

2) Faculty of Agriculture, Ain Shams University 3) Institute of Environmental Studies and Research, Ain Shams University 4) Desert Research Center

\section{ABSTRACT}

The natural resources (soil-plant-animal-aquatic situation) in North Sinai are experiencing a deterioration due to the impact of climatic, environmental and the human activities. This has led to a reduction in biodiversityand desertication of wide areas in North Sinai which decrease the income of the farmers.It important study the various effects of agriculture projects to adapt with climatic effects to achieve the desired uses of the available resources and the sustainability of these projects. Therefore, the aim of this research is to evaluate the ability of prouject to solve the proplems of faremers in North Sinai. The research depends on the use of descriptive analytical approach to present and analyze the research problem as well as quantitative analysis to measure the production and economic efficiency of the project based on achieving objectives through the various statistical methods. It also relied on secondary and preliminary data.

The predictive value of the effect of rainfall on productivity was $0.544,0.097,-0.022,3.419,37.719 \mathrm{~kg} /$ feddan for alfalfa, barley, feed beet, pearl millet and sorghum respectively, while the predictive values of the effect of temperature on productivity were $-0.523,-0.18,4.900$, $1.818,1.493 \mathrm{~kg} /$ feedan respectively. Theeffect of humidity were $0.637,0.118,0.861,-5.658,-28.471 \mathrm{~kg} / \mathrm{feedan}$ respectively. For the

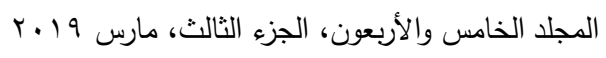


effect of wind speed on productivity, the values were $-3.613,-0.112$, $3.857,6.148,-1.624$ respectively

The effect of climate change factors was 15.1, 52.8, 62.8, 20.4 and $39 \%$ on the productivity of alfalfa, barley, fodder, pearl millet and sorghum crops, respectivily, while $84.9,47.2,37.2,79.6$ and $61 \%$ were related to the effect of other environmental factors and human productivity.

For the economic evaluation of the project, it was noted that the use of integrated agricultural practices with the start of the project activities led to an evolution in the economic productivity indicators of the cultivated crops whem compared with the use of traditional agricultural practices before the start of the project activities. (prouctivity - total costs - total revenues - net profit - ratio of revenues to costs - Investor's revenue criterion). Therefore, the study recommends ito increase the number of agricultural projects in North Sinai, which help farmers on modern agricultural techniques in order to achieve the best use of the available resources in the studied region and work on producing new strains of crops that adapt to the conditions of the region to increase its productivity. 